\title{
Comparative Study of Two Digestion Methods for Heavy Metal Analysis in a Moss Species Collected in Ado-Ekiti, Nigeria
}

\author{
Adedeji Olayinka Adebiyi ${ }^{*}$, Patrick Olugbenga Tedela
}

Department of Plant Science and Biotechnology, Ekiti State University, Ado Ekiti, Ekiti State, Nigeria

DOI: $10.36347 /$ sajb.2020.v08i06.008

| Received: 16.06.2020 | Accepted: 24.06.2020 | Published: 26.06 .2020

*Corresponding author: Adedeji Olayinka Adebiyi

\section{Abstract}

Original Research Article

This study was conducted to evaluate the efficiency of two digestion methods in determining heavy metal concentrations in a moss species. Samples of the moss Barbula lambaranensis were collected from seven major roadsides in Ado-Ekiti, Nigeria. In each location, three subsamples were collected and pooled to form a composite sample. Each was then divided into two parts. The moss samples were cleaned of extraneous material, oven dried at $50^{\circ} \mathrm{C}$ for $24 \mathrm{hrs}$ and digested using two different digestion methods namely dry digestion and wet digestion to recommend the more efficient digestion method. Digested samples were analysed for six heavy metals namely iron $(\mathrm{Fe})$, nickel $(\mathrm{Ni})$, copper $(\mathrm{Cu})$, chromium $(\mathrm{Cr})$, lead $(\mathrm{Pb})$ and cadmium $(\mathrm{Cd})$ using atomic absorption spectrometry. Results revealed that both digestion methods gave similar and comparable results. Total mean concentrations $(\mathrm{mg} / \mathrm{kg})$ of $\mathrm{Fe}, \mathrm{Ni}, \mathrm{Cu}, \mathrm{Cr}$ and $\mathrm{Pb}$ in the moss samples were $2758.57,3.06,18.93,1.78$ and 0.58 respectively using dry digestion method while mean concentrations of Fe (3409.05), $\mathrm{Ni}$ (3.56), $\mathrm{Cu}$ (20.37), $\mathrm{Cr}$ (2.21) and $\mathrm{Pb}$ (0.61) were observed in the moss samples using wet digestion method. Cadmium was below detection limits in both cases. Statistical analyses revealed that there were no significant differences between the concentrations of the heavy metals obtained by both digestion methods. This indicates that both digestion methods are equally precise and reliable for the preparation of moss samples for heavy metal analysis.

Keywords: Moss, heavy metals, wet digestion, dry digestion, AAS.

Copyright @ 2020: This is an open-access article distributed under the terms of the Creative Commons Attribution license which permits unrestricted use, distribution, and reproduction in any medium for non-commercial use (NonCommercial, or CC-BY-NC) provided the original author and source are credited

\section{INTRODUCTION}

One of the major public challenges being experienced by most of the developing countries today is air pollution [1]. Recently, it has continued to pose a major threat to human health and the environment. Human activities have continued to deteriorate the environment, thus endangering it [2]. For instance, metals that once occurred naturally in trace quantities in the environment are now abundant and hazardous as a result of human/anthropogenic activities. Some of these activities include fossil fuel combustion, industrialization, many temperature driven reactions and incineration of domestic wastes [3, 4]. Heavy metals like $\mathrm{Cd}, \mathrm{Pb}, \mathrm{Cu}$, and $\mathrm{Zn}$ when released find their way into the soil usually through rain and wind [5]. It has been reported that metals such as $\mathrm{Pb}, \mathrm{Cd}, \mathrm{Hg}$, $\mathrm{Ni}$ and As could pose potential health hazards [6]. Some of them could find their ways to man through food chain and in that course, attack specific sites or organs which may result to diseases [7].

The assessments of the level of heavy metals in the environment and the threat they constitute have being a major challenge to the environmental scientists. Some of the methods adopted to initially address this challenge are biomonitoring and direct measurements of air quality. However, biomonitoring has been widely adopted recently and considered as an alternative to direct ambient air measurement due to the fact that it provides information on both the quantity of pollutants and their impacts on the prevalence and conditions of the biomonitors. Moreover, it is also cheaper. Though the direct measurement of air quality is also reliable, it is expensive and the risk of contamination at low concentration is high [8]. Over the years, mosses have proven to be excellent bioindicators of pollution. In fact, they have become indispensable tools in the biomonitoring of air pollutants. Their use in this regard may be attributed to their lack of a true root system which makes them to depend on atmospheric deposition for the intake of water, nutrients and consequently toxic substances [9]. An added advantage of mosses as biomonitors is that it does not involve the use of expensive equipment. The simplicity of analyses of metal concentrations in mosses, fewer problems of contamination and the results which reveal integrated exposure over the years make mosses good bioindicators 
[10]. Furthermore, the ability of these plants to grow abundantly and survive in natural habitats as well as urban areas and industrial locations is also considered as an added advantage [11]. Besides these, mosses are naked, small-sized, have the ability to tolerate different environmental conditions and also have high efficiency to accumulate heavy metals without choice [12]. Other advantages include perenniality, ease of collection, wide distribution and large capacity for cat ion exchange [13]. Mosses also grow on substrates or areas where higher plants find difficult to survive. Hence, they have little or no competition [14].

Mosses have been widely and successfully utilized for biomonitoring of heavy metals by different researchers [15, 16]. As such, different digestion methods have been used to prepare moss samples for heavy metal analysis [17, 18]. Considering the health hazards associated with the occurrence of heavy metals in the environment, the need to accurately determine their concentrations in the environment is inevitable for safety assurance. Moreover, the importance of sample preparation in ensuring accurate and reliable results in spectroscopic studies cannot be overemphasized.

Thus, the aim of this study was to compare the efficiency of two digestion methods namely dry and wet digestion in determining the concentrations of heavy metals in mosses.

\section{MATERIALS AND METHODS Collection of Sample}

Moss samples were collected from seven major roadsides in Ado-Ekiti, Nigeria in July, 2019 with the aid of a sharp knife. The geographical coordinates and the altitudes of the locations are shown in Table-1. In each location, three subsamples were collected and pooled to form a composite sample. Each was then weighed and divided into two equal parts. Collections were kept in sterilized nylon bags and labelled accordingly. These were taken to the laboratory for identification as well as analyses for some heavy metals.

Table-1: Geographical coordinates and altitudes of the locations
\begin{tabular}{|l|l|l|l|}
\hline Location & Longitude/E & Latitude/N & Altitude (m) \\
\hline Fajuyi road & $7^{0} 30^{\prime} 2280.49$ & $5^{0} 12^{\prime} 775.47$ & 466 \\
\hline Ajilosun road & $7^{0} 36^{\prime} 2205.65$ & $5^{0} 13^{\prime} 804.43$ & 450 \\
\hline Irona road & $7^{0} 37^{\prime} 2222.07$ & $5^{0} 13^{\prime} 782.50$ & 463 \\
\hline Odo Ado road & $7^{0} 37^{\prime} 2238.90$ & $5^{0} 13^{\prime} 812.45$ & 458 \\
\hline Adebayo road & $7^{0} 39^{\prime} 2355.83$ & $5^{0} 13^{\prime} 842.28$ & 412 \\
\hline Old garage & $7^{0} 37^{\prime} 2238.90$ & $5^{0} 13^{\prime} 812.45$ & 458 \\
\hline Basiri road & $7^{0} 35^{\prime} 2240.45$ & $5^{0} 12^{\prime} 738.31$ & 447 \\
\hline
\end{tabular}

\section{Identification of moss samples}

Moss samples were identified in the herbarium of the Department of Plant Science and Biotechnology, Ekiti State University, Ado Ekiti using all diagnostic and morphological features. The identified moss, Barbula lambaranensis is the most abundant moss species in Ekiti State [19]. Voucher specimens were deposited in the herbarium.

\section{Chemicals}

All the chemicals used in this study were of analytical grades. $\mathrm{HNO}_{3}$ and $\mathrm{HClO}_{4}$ were obtained from Perkin Elmer USA. Distilled water was used throughout the study.

\footnotetext{
Sample preparation and Digestion of moss samples

Debris such as plant remains and soil particles were removed from the moss samples. They were then washed under running water. They were oven dried at $50^{\circ} \mathrm{C}$ for $24 \mathrm{hrs}$ after which they were then ground. Ground samples were thereafter subjected to two different digestion methods namely dry digestion and wet digestion.
}

\section{Dry Digestion}

A crucible was prepared by igniting in a muffle furnace at $550^{\circ} \mathrm{C}$ for $12 \mathrm{hrs}$ and later transferred into a desiccator containing active desiccant while still hot to cool. After cooling, the crucible was weighed and $1 \mathrm{~g}$ of the sample was added into the crucible. The crucible was then put in the muffle furnace and ignited at $550^{\circ} \mathrm{C}$ until all the organic components have burnt off remaining the ash. The crucible was transferred into a desiccator when the furnace temperature reduced to about $200^{\circ} \mathrm{C}$ and allowed to cool. Then the ash was transferred into a beaker and $20 \mathrm{ml}$ of $\mathrm{HNO}_{3}$ was added. The sample with the digesting solvent was placed on a hot plate in the fume cupboard until ash fully dissolved. The beaker and its contents after the digestion were allowed to cool to the room temperature. The mixture was then filtered into $100 \mathrm{ml}$ volumetric flask and made up to the mark with distilled water.

\section{Wet Digestion}

$1 \mathrm{~g}$ of the ground sample was weighed into a pyrex beaker and $10 \mathrm{ml}$ of conc. $\mathrm{HNO}_{3}$ was added and allowed to soak for 30 mins. Then, $3 \mathrm{ml}$ of $60 \%$ perchloric acid was added. This was placed on a hot plate and heated at $350^{\circ} \mathrm{C}$ until frothing stopped and $\mathrm{HNO}_{3}$ almost evaporated. Then, a watch glass was placed on 
the beaker and heating continued until the sample turned light straw in colour. This was then removed from the hot plate and cooled. Then, the watch glass was rinsed into the sample and it was filtered into $100 \mathrm{ml}$ volumetric flask and made up to the mark with distilled water.

\section{Determination of Heavy Metals in Moss Samples}

The selected heavy metals in this study were chosen according to the significance of their occurrence in environments [20]. Working standards of iron, copper, nickel, chromium, lead and cadmium solutions were made from each of the heavy metals solution of $100 \mathrm{~g} / \mathrm{l}$ stock solutions of the metals. Blank was also prepared using the same volume of reagents used for the digestion and filtration. The concentrations of the heavy metals in the digested samples were determined using a Buck Scientific Atomic Absorption Spectrophotometer (Model: 210VGP) at various wavelengths of the metals and using specific cathode lamps of each metal. Quantification of the metals was based upon calibration curves of standard solutions of metals. Blanks were included in each batch of analysis. The accuracy of the analytical method was evaluated using certified reference standards. The concentrations of the metals were calculated using the formula:

Concentration $(\mathrm{mg} / \mathrm{kg})=\underline{\mathrm{mg} / \mathrm{L} \text { reading from AAS X } 100}$ weight of sample (g)

\section{STATISTICAL ANALYSIS}

The mean concentrations of the heavy metals in the moss samples were obtained and recorded. Analysis of variance (ANOVA) was used to analyse the differences in metal concentrations in different locations. The differences in the concentrations of metals obtained by the two digestion methods were analysed using t-Test.

\section{RESULTS AND DISCUSSION}

The concentrations $(\mathrm{mg} / \mathrm{kg})$ of $\mathrm{Fe}, \mathrm{Ni}, \mathrm{Cu}, \mathrm{Cr}$ and $\mathrm{Pb}$ in moss samples subjected to dry digestion method ranged from 1250.12 to $5660.24,2.10$ to 4.56 , 14.15 to 24.110 .24 to 6.09 and 1.00 to 2.00 respectively (Table2) while it ranged from 1118.67 to $7480.05,1.80$ to $6.28,14.79$ to $28.03,0.88$ to 6.13 and 1.02 to 2.07 respectively in moss samples subjected to wet digestion method (Table 3). The variation observed in the concentrations of the heavy metals across the locations is in line with previous works and may be attributed to variations in the anthropogenic activities around the locations $[15,21]$.

The total mean concentrations of $\mathrm{Fe}, \mathrm{Ni}, \mathrm{Cu}, \mathrm{Cr}$ and $\mathrm{Pb}$ in moss samples subjected to dry digestion method were 2758.57, 3.06, 18.93, 1.78 and 0.58 respectively while total mean concentrations of $\mathrm{Fe}$ (3409.05), Ni (3.56), Cu (20.37), Cr (2.21) and $\mathrm{Pb}$ (0.61) were obtained in moss samples digested with the wet digestion method. The total mean concentrations of all the heavy metals in the present study are lower than reported mean values [22]. Mean Fe concentration in the present study compared favourably with reported mean value [23] but higher than reported range [24]. The mean $\mathrm{Cu}$ concentration observed in this study was higher than the mean value reported in India [23]. The concentrations of $\mathrm{Ni}, \mathrm{Cr}$ and $\mathrm{Pb}$ in the present study were also lower than the values reported at Ilorin, Nigeria [16]. Reported sources of heavy metals in the environment include industrial activities, dead and decomposing animals and vegetation, domestic activities, fall out of atmospheric particulate [25]. Other reported sources of heavy metals in the environment include automobiles, incineration of domestic wastes, power station and fossil fuel combustions $[4,26]$.

In the present study, the prevalence of the metal concentrations was as follows: $\mathrm{Fe}>\mathrm{Cu}>\mathrm{Ni}>\mathrm{Cr}>\mathrm{Pb}>$ Cd (Fig 1 \& 2). This may be attributed to variations in the uptake efficiency of mosses for individual metals [27]. It has been reported that several factors affect the uptake efficiency by mosses [28, 29].

A comparison between the concentrations of the heavy metals in each of the locations in moss samples subjected to dry and wet digestion methods is shown in Fig 3-7. Both methods gave similar and comparable results. However, statistical analysis (Table 4) revealed that no significant differences existed between the concentrations of the heavy metals in moss samples subjected to dry and wet digestion methods. This result tends to agree with the previous works $[30,31]$.

Table-2: Mean concentrations $(\mathrm{mg} / \mathrm{kg})$ of heavy metals in a moss species, $B$. lambaranensis subjected to dry digestion method

\begin{tabular}{|l|l|l|l|l|l|l|}
\hline Location & Pb & Cd & Cr & Fe & Ni & Cu \\
\hline Fajuyi road & BDL & BDL & $0.61 \mathrm{e}$ & $3738.65 \mathrm{~b}$ & $3.12 \mathrm{~d}$ & $15.26 \mathrm{f}$ \\
\hline Ajilosun road & BDL & BDL & $0.54 \mathrm{f}$ & $1340.01 \mathrm{f}$ & $2.42 \mathrm{e}$ & $17.10 \mathrm{e}$ \\
\hline Irona road & $1.00 \mathrm{~b}$ & BDL & $6.09 \mathrm{a}$ & $1250.12 \mathrm{~g}$ & $2.10 \mathrm{~g}$ & $24.00 \mathrm{a}$ \\
\hline Odo Ado road & BDL & BDL & $2.91 \mathrm{~b}$ & $2520.23 \mathrm{~d}$ & $3.41 \mathrm{c}$ & $18.00 \mathrm{~d}$ \\
\hline Adebayo road & $2.00 \mathrm{a}$ & BDL & $0.80 \mathrm{~d}$ & $2980.43 \mathrm{c}$ & $3.56 \mathrm{~b}$ & $23.01 \mathrm{~b}$ \\
\hline Old garage & $1.05 \mathrm{~b}$ & BDL & $1.16 \mathrm{c}$ & $5660.24 \mathrm{a}$ & $4.56 \mathrm{a}$ & $21.11 \mathrm{c}$ \\
\hline Basiri road & BDL & BDL & $0.34 \mathrm{~g}$ & $1820.21 \mathrm{e}$ & $2.30 \mathrm{f}$ & $14.02 \mathrm{~g}$ \\
\hline Mean \pm S.D. & $0.58 \pm 0.76$ & 0.00 & $1.78 \pm 2.01$ & $2758.57 \pm 1501.61$ & $3.06 \pm 0.84$ & $18.93 \pm 3.59$ \\
\hline
\end{tabular}

BDL - Below Detection Limit

Means with the same letters within columns are not significantly different at $\mathrm{p}<0.05$ 
Table-3: Mean concentrations (mg/kg) of heavy metals in a moss species, $B$. lambaranensis subjected to wet digestion method

\begin{tabular}{|l|l|l|l|l|l|l|}
\hline Location & Pb & Cd & Cr & Fe & Ni & Cu \\
\hline Fajuyi road & BDL & BDL & $0.88 \mathrm{e}$ & $5618.33 \mathrm{~b}$ & $3.02 \mathrm{~d}$ & $20.89 \mathrm{c}$ \\
\hline Ajilosun road & BDL & BDL & $0.75 \mathrm{f}$ & $1639.67 \mathrm{f}$ & $2.10 \mathrm{f}$ & $22.03 \mathrm{~b}$ \\
\hline Irona road & $1.02 \mathrm{c}$ & BDL & $6.13 \mathrm{a}$ & $1118.67 \mathrm{~g}$ & $2.40 \mathrm{e}$ & $18.00 \mathrm{f}$ \\
\hline Odo Ado road & BDL & BDL & $4.19 \mathrm{~b}$ & $2560.01 \mathrm{~d}$ & $4.20 \mathrm{c}$ & $18.79 \mathrm{e}$ \\
\hline Adebayo road & $2.07 \mathrm{a}$ & BDL & $1.43 \mathrm{c}$ & $3173.67 \mathrm{c}$ & $5.12 \mathrm{~b}$ & $20.03 \mathrm{~d}$ \\
\hline Old garage & $1.17 \mathrm{~b}$ & BDL & $1.22 \mathrm{~d}$ & $7480.05 \mathrm{a}$ & $6.28 \mathrm{a}$ & $28.03 \mathrm{a}$ \\
\hline Basiri road & BDL & BDL & $0.88 \mathrm{e}$ & $2273.03 \mathrm{e}$ & $1.80 \mathrm{~g}$ & $14.79 \mathrm{~g}$ \\
\hline Mean \pm S.D. & $0.61 \pm 0.81$ & 0.00 & $2.21 \pm 2.02$ & $3409.05 \pm 2187.50$ & $3.56 \pm 1.60$ & $20.37 \pm 3.89$ \\
\hline
\end{tabular}

BDL - Below Detection Limit

Means with the same letters within columns are not significantly different at $\mathrm{p}<0.05$

Table-4: t-Test

\begin{tabular}{|l|l|l|l|l|l|l|}
\hline Fe & & & & & & \\
\hline Sample & $\mathrm{N}$ & Mean & SD & Df & t-Cal & Pr>t \\
\hline WD & 14 & 3409.05 & 2212.56 & 26 & 0.921 & 0.365 \\
\hline DD & 14 & 2757.59 & 1501.61 & & & \\
\hline Ni & & & & & & \\
\hline Sample & N & Mean & SD & Df & t-Cal & Pr>t \\
\hline WD & 14 & 3.56 & 1.62 & 26 & 1.015 & 0.323 \\
\hline DD & 14 & 3.06 & 0.84 & & & \\
\hline Cu & & & & & & \\
\hline Sample & N & Mean & SD & Df & t-Cal & Pr $>t$ \\
\hline WD & 14 & 20.36 & 3.93 & 26 & 0.953 & 0.349 \\
\hline DD & 14 & 18.93 & 3.59 & & & \\
\hline Cr & & & & & & \\
\hline Sample & N & Mean & SD & Df & t-Cal & Pr>t \\
\hline WD & 14 & 2.22 & 2.02 & 26 & 0.582 & 0.566 \\
\hline DD & 14 & 1.78 & 2.01 & & & \\
\hline Pb & & & & & & \\
\hline Sample & N & Mean & SD & Df & t-Cal & Pr $>t$ \\
\hline WD & 14 & 0.61 & 0.81 & 26 & 0.930 & 0.897 \\
\hline DD & 14 & 0.58 & 0.76 & & & \\
\hline
\end{tabular}

WD: Wet Digestion; DD: Dry Digestion

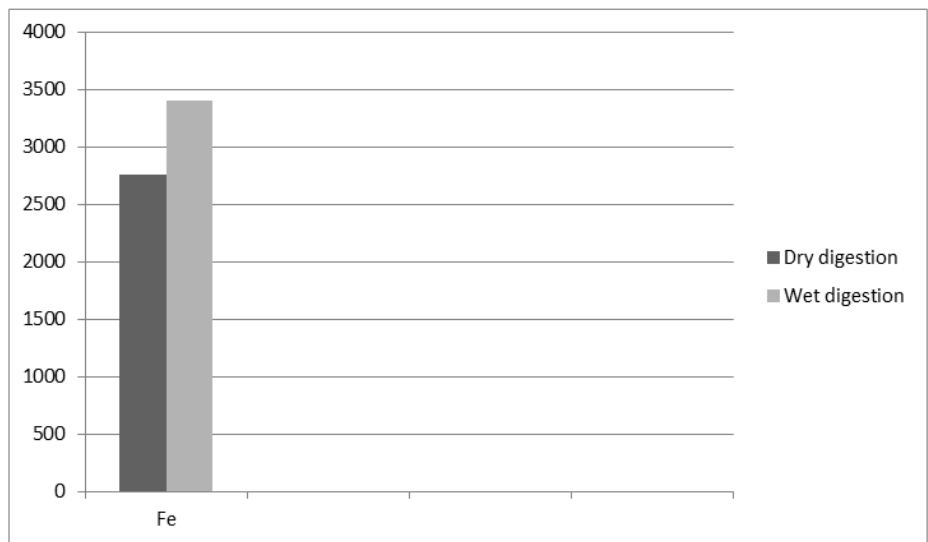

Fig-1: Comparison of total mean values of Fe concentrations $(\mathrm{mg} / \mathrm{kg})$ in moss samples subjected to dry and wet digestion methods 


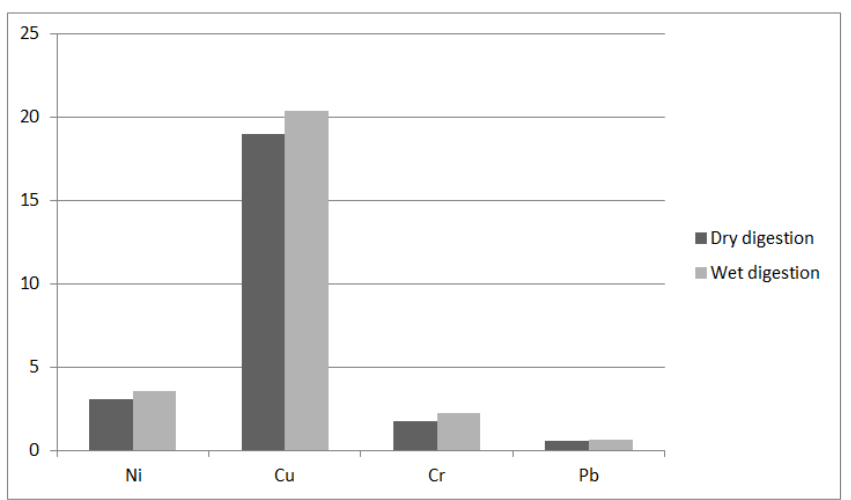

Fig-2: Comparison of total mean values of $\mathrm{Ni}, \mathrm{Cu}, \mathrm{Cr}$ and $\mathrm{Pb}$ concentrations $(\mathrm{mg} / \mathrm{kg})$ in moss samples subjected to dry and wet digestion methods

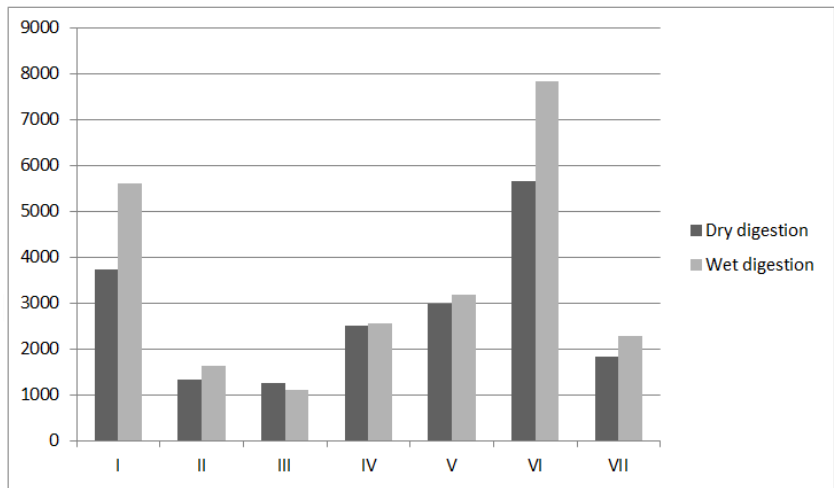

Fig-3: Comparison of Fe concentrations ( $\mathrm{mg} / \mathrm{kg})$ in moss samples subjected to dry and wet digestion methods in all the locations I: Fajuyi road, II: Ajilosun road, III: Irona road, IV: Odo Ado road, V: Adebayo road, VI: Old garage, VII: Basiri road

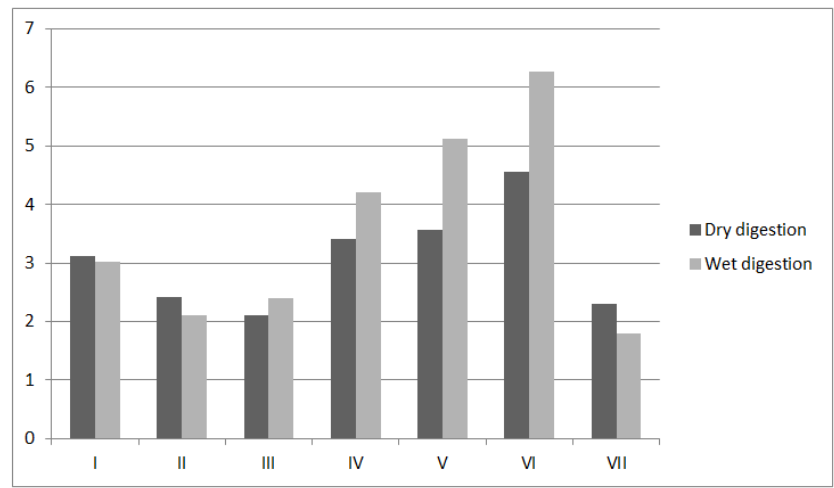

Fig-4: Comparison of Ni concentrations ( $\mathrm{mg} / \mathrm{kg}$ ) in moss samples subjected to dry and wet digestion methods in all the locations I: Fajuyi road, II: Ajilosun road, III: Irona road, IV: Odo Ado road, V: Adebayo road, VI: Old garage, VII: Basiri road

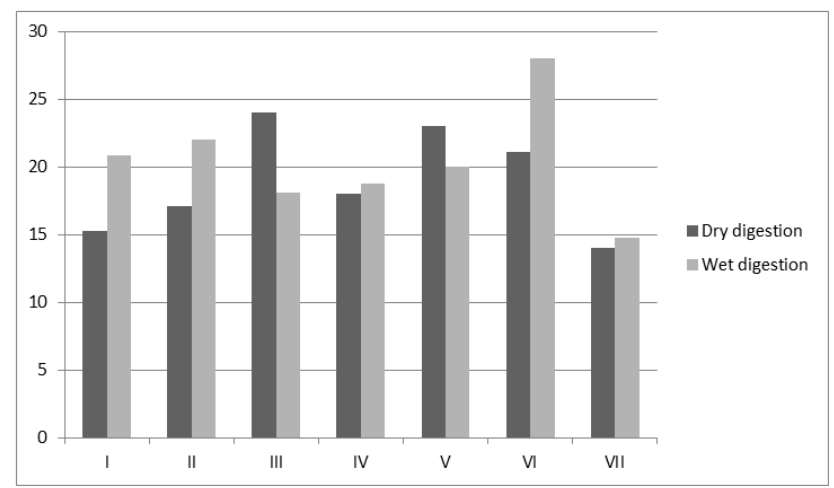

Fig-5: Comparison of Cu concentrations (mg/kg) in moss samples subjected to dry and wet digestion methods in all the locations I: Fajuyi road, II: Ajilosun road, III: Irona road, IV: Odo Ado road, V: Adebayo road, VI: Old garage, VII: Basiri road 


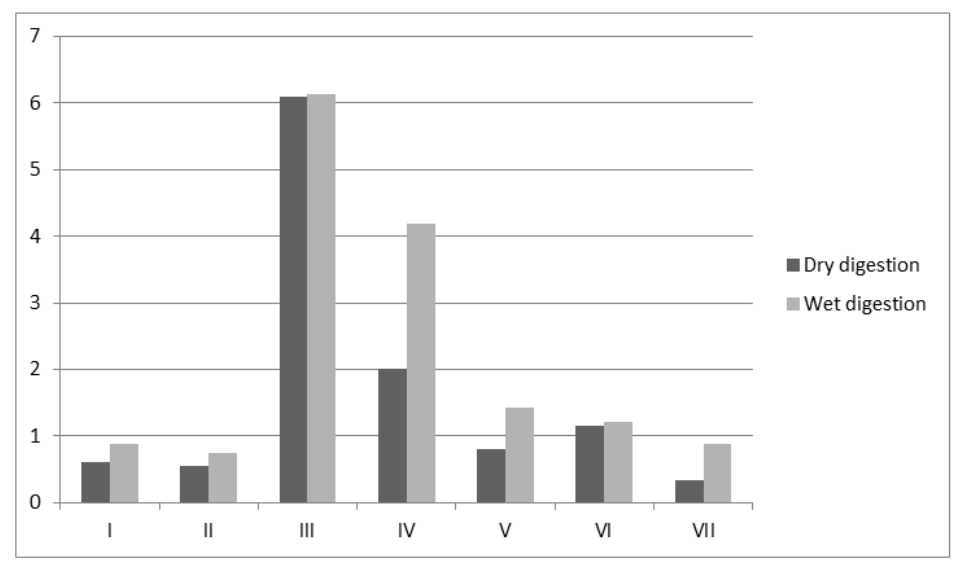

Fig-6: Comparison of $\mathrm{Cr}$ concentrations $(\mathrm{mg} / \mathrm{kg})$ in moss samples subjected to dry and wet digestion methods in all the locations I: Fajuyi road, II: Ajilosun road, III: Irona road, IV: Odo Ado road, V: Adebayo road, VI: Old garage, VII: Basiri road

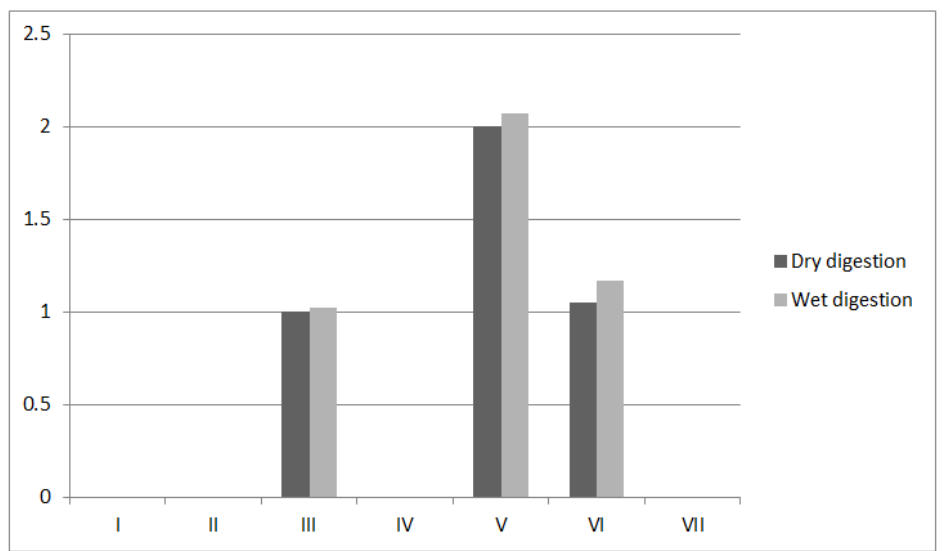

Fig-7: Comparison of $\mathrm{Pb}$ concentrations $(\mathrm{mg} / \mathrm{kg})$ in moss samples subjected to dry and wet digestion methods in all the locations I: Fajuyi road, II: Ajilosun road, III: Irona road, IV: Odo Ado road, V: Adebayo road, VI: Old garage, VII: Basiri road

\section{CONCLUSION}

The results of the present study have confirmed the occurrence of heavy metals in the atmosphere as the plant used in this study does not have true roots hence, it takes up water, nutrients and consequently any pollutant through atmospheric deposition through the outer surface. The study revealed that there were no significant differences between the concentrations of the heavy metals in moss samples subjected to dry and wet digestion methods. This suggests that both methods are equally precise and reliable for the preparation of moss samples for heavy metal analysis.

\section{REFERENCES}

1. Davis MF, Rapparport A. Air quality in developing world, disaster and conflict zones. The case of post-earthquake Haiti. Sci Tot Environ. 2014; 496: 22-25.

2. Ferner DJ. Toxicity, heavy metals. Institute of Environmental Conservation and Research. Emerging Medicine Journal, 2001;2(5).

3. Krolak E. Heavy metal content in falling dust, soil and dandelion (Taraxacumofficinale Webb) in southern Podlasie lowland.Electronic Journal of Polish Agricultural Universities. 2001; 4(1):1-13.
4. Caselles J, Colliga C, Zornoza R. Evaluation of trace element pollution from vehicle emissions in Petunia plants. Water, Air and Soil Pollution. 2002; 136(1-4):1-9.

5. Kho FWL, Law DL, Ibrahim, SH and Sentian J. Carbon monoxide levels along roadsides. Int $\mathrm{J}$ Environm Sci Tech. 2007; 4(1):27-34.

6. Ademoroti CMA. Environmental chemistry and toxicology. Foludex Press Ltd., Ibadan. 1996; 171 201.

7. Audu AA, Lawal AO. Variations in metal contents of plants in vegetable garden sites in Kano metropolis. J Applied Sci and Environ Manag. 2005; 10(2): 105-109.

8. Markert BA, Breure AM and Zeichmeister HG. Definitions, strategies and principles for bioindication / biomonitoring of the environment. Elsevier, Oxford. 2003; 3-39.

9. Culicov OA, Frontasyeva, M, Steinnes E. Atmospheric deposition of heavy metals around the lead and copper-zinc smelters in Baia Mare, Romania studied by moss monitoring technique, Neutron activation analysis and flame atomic absorption spectrometry. Journal of Radioanalytical and Nuclear Chemistry, 2002; 254(1):109-115. 
10. Poikolainen J. Mosses, epiphytic lichens and tree bark as biomonitors for air pollutants - specifically for heavy metals in regional surveys. Faculty of Science, Department of Biology, University of Oulu; The Finnish Forest Research Institute, Muhos Research Station, Oulu, Finland, 2004.

11. Aceto M, Abollino A, Conca R, Malandrino M, Mentasti E, Sarzanini C. The use of mosses as environmental metal pollution indicators. Chemosphere, 2003; 50:333-342.

12. Csintalan Z, Juhtsz A, Benk S, Raschi A, Tuba Z. Photosynthetic response of forest floor moss species to elevated $\mathrm{CO}_{2}$ levels by natural $\mathrm{CO}_{2}$ vents. Cer Res Com. 2005; 33: 177- 180.

13. Charkrabortty S, Jha SK, Puranik VD, Paraktar GT. Use of mosses and lichens as biomonitors in the study of air pollution near Mumbai. Evansia, 2006; 23:1-8.

14. Meenks JLD, Tuba Z. Bryophytes as biological indicators. In: Biological indicators in environmental protection, Kovacs M. (Ed), Ellis Howard Pub. Ltd., Chichester, Budapest. 1991, 169-191.

15. Jiang Y, Fan M, Hu R, Zhao J and Wu, Y. Mosses are better than leaves of vascular plants in monitoring atmospheric heavy metal pollution in urban areas. Int. J. Environ. Res. Public Health, 2018; 15: 1105.

16. Fatoba PO, Oduekun TI. Assessment of metal deposition in Ilorin metropolis using mosses as bioindicators. Nig. J of Pure Applied Sci, 2004; 19 : 1549-1552.

17. Uddin ABM, Khalid RS, Alaama M, Abdualkader, AM, Kasmuri A, Abbas SA. Comparative study of three digestion methods for elemental analysis in traditional medicine products using atomic absorption spectrometry. Journal of Analytical Science and Technology, 2016; 7(6).

18. Fatoba PO, Ogunkunle CO, Oyedeji S, Salawudeen MB. Heavy metal depositions around some petroleum products depots in Nigeria using mosses as biomonitors. The Bioscientist, 2013; 1(1): 99-105.

19. Adebiyi AO, Oyeyemi SD. Distribution of mosses in Ekiti State, Nigeria. New York Sci Journal, 2013; 6(6): 23-25.
20. Lantzy RJ and Mackenzie FT. Atmospheric trace metals: global cycles and assessment of man s impact. Geochim Cosmochim Acta, 1979; 43: 511-525.

21. Shakya K, Chettri MK, Sawidis T. Appraisal of some mosses for bio monitoring airborne heavy metals in Kathmandu valley. Eco print, 2001; 8(1):69-75.

22. Chen YE, Yuan S, Wang L. Comparison of heavy metal accumulation capacity of some indigenous mosses in Southwest China cities: a case study of Chengdu city. Plant Soil Environ. 2010; 56 (2): 60-66.

23. Guray U, Muhmmet O, MahirInce. Atmospheric Heavy Metal Deposition In Duzce Province by Using Mosses as Biomonitors. PSP. 2007;16(2).

24. Ogunkunle CO, Fatoba, PO and Okewole GA. Mosses as bio monitors of heavy metal deposition in the atmosphere. IJES, 2012; 1(2): 56-62.

25. Babich H, Stotzky G. Environmental Biogeochemistry. Ecol. Bull. (Stockholm). 1983; 35:315-323.

26. Tonguc O. Determination of heavy metal levels in some species around some thermic power stations. Turk J Bot. 1998; 22: 171-180.

27. Berg T, Royset O, Steinnes E. Moss Hylocomium splendens used as bio monitor of atmospheric trace element deposition: Estimation of uptake efficiencies. Atmos. Environ. 1995; 29: 353-360.

28. Gjengedal E, Steinnes E. Uptake of metal ions in moss from artificial precipitation. Environ. Monit. Assess. 1990; 14:77-87.

29. Couto JA, Fernandez J, Aboal, JR, Carballeira A. Active biomonitoring of element uptake with terrestrial mosses: A comparison of bulk and dry depositions. Sci. Total Environ. 2004; 324: 211-222.

30. Maxhuni A, Lazo P, Paqarizi M. Comparison of two analytical techniques for lead determination in soils and moss samples. American Journal of Environmental Sciences, 2012; 8(4): 412-416.

31. Tuzen M. A comparison of sample preparation procedures for the determination of heavy metals in lichen samples by GFAA. Analytical Letters, 2002; 35(10): 1667-1676. 